\title{
Global Health Watch 5: An Alternative World Health Report
}

Matheus Falcão', Muna Odeh², Silvia Giugliani ${ }^{\mathbf{3}}$

DOI: 10.1590/0103-11042020S117

\section{Apresentação}

O Global Health Watch: An Alternative World Health Report ${ }^{1}$ é um projeto concebido em 2003 como um esforço de ativistas e acadêmicos da área de saúde de produzir uma perspectiva alternativa no campo da saúde global, compilando análises políticas, debates, relatos de experiências e pareceres técnicos. Até o presente, foram publicadas cinco edições, em 2005, 2008, 2011, 2014 e 2018. A quinta edição do GHW contou com a coordenação de cinco organizações da sociedade civil: o Movimento pela Saúde dos Povos, a Associação Latino-Americana de Medicina Social (Alames) a Health Poverty Action, a Fundação Medico International, a Third World Network e a Medact.

\section{Movimento global de saúde}

1 Universidade de São Paulo (USP), Núcleo de Pesquisas em Direito Sanitário (NAP-Disa) - São Paulo (SP), Brasil. matheus.falcao@usp.br

2 Universidade de Brasília (UnB) - Brasília (DF)

Brasil.

3 Pontifícia Universidade Católica do Rio Grande do Sul (PUC-RS) - Porto Alegre (RS), Brasil.
Ganha força nos últimos tempos a ideia de movimentos globais, transnacionais ou do fortalecimento de uma sociedade civil global, no intuito de organizar politicamente os povos para além das fronteiras nacionais e enfrentar as questões que ameaçam a efetivação de uma vida digna global. Hoje, frente à estrutura do mundo, a luta por direitos se torna cada vez mais insuficiente se limitada ao âmbito nacional. O poder já não está apenas nos países, mas sim concentrado em grandes corporações globais e organismos que transcendem fronteiras. Entidades como o Banco Mundial assumem protagonismo acentuado na orientação de políticas públicas.

O Movimento pela Saúde dos Povos se organiza em círculos nacionais e regionais,em cerca de 70 países, tentando aproximar entidades e ativistas comprometidos com a ampliação do acesso e a plena realização da saúde enquanto direito. Fundado na Primeira Assembleia Mundial de Saúde dos Povos, em Bangladesh, em 2000, orienta-se pela Carta pela Saúde dos Povos. Desde então, foi corresponsável pela organização de outras três: no Equador, em 2005, na África do Sul, em 2012 e novamente em Bangladesh, em 2018. Sua coordenação compreende representantes de todas as regiões do globo, atuando ainda em parceria com entidades de relevância regional, como a Alames, na América Latina. Além disso, desenvolve projetos de monitoramento das instâncias decisórias da Organização Mundial da Saúde (OMS).

\section{O Global Health Watch 5 (GHW5)}

A estrutura do Global Health Watch tenta englobar tanto análises sobre saúde global quanto relatos de experiências locais de 
ampliação e fortalecimento da saúde como direito humano, revitalizando os preceitos de Alma-Ata. Nesta quinta edição, o foco está em duas questões: os Objetivos de Desenvolvimento Sustentável (ODS) da Organização das Nações Unidas (ONU) e as mudanças de protagonismo na governança global em saúde, dos Estados nacionais para fundações privadas internacionais e corporações.

A primeira seção, intitulada 'Arquitetura política e econômica global', propõe-se a estabelecer relações entre a atual configuração do poder global e certas intervenções em saúde pouco efetivas, que não fortalecem sistemas de saúde nacionais, apenas levam tecnologias de saúde ao contexto local, tema que inclusive já foi muito explorado na literatura sobre o campo da saúde global ${ }^{2}$. Em seguida, a seção 'Sistemas de saúde: questões atuais e debates' apresenta questões relevantes sobre sistemas de saúde a partir de experiências locais e regionais em diferentes áreas do globo. A próxima seção, 'Para além dos serviços de saúde', aborda os determinantes políticos, sociais e ambientais de saúde, seguida da quarta, 'Observando', que apresenta resultados do monitoramento de processos e instituições globais, como a OMS. A última seção, 'Resistência, ações e mudança' trata de experiências concretas de ações de resistência por parte de movimentos sociais e da sociedade civil pela ampliação do acesso à saúde em diferentes partes do mundo, pautando formas alternativas de alcançar o bem-estar comunitário.

Os ODS foram estabelecidos em 2015 pela ONU como um conjunto de 17 objetivos a serem atingidos pela humanidade até o ano de 2030. O terceiro objetivo contempla a saúde e o bem-estar humanos e reúne um conjunto de objetivos específicos, destacando-se o 3.8, que se tornou a tônica do discurso oficial mais recente na área: a cobertura universal de saúde. Ainda que a proposta contemple esforços para garantir a aceitabilidade de serviços públicos de saúde e reconheça a necessidade de financiamento público, por exemplo, no GHW5, discute-se uma proposta mais ambiciosa e com fortes indicativos de maior eficiência e resolutividade, que envolve trazer o controle dos serviços de saúde para a comunidade e se pautar pelo conceito mais abrangente de Atenção Primária à Saúde, conforme a Declaração de Alma-Ata.

A questão do controle comunitário está na essência do Sistema Único de Saúde (SUS) e encontra respaldo em diversas outras experiências pelo mundo. No GHW5, são apresentados exemplos de experiências exitosas de controle comunitário. Na Austrália, diversos serviços estão sendo descentralizados para gestão comunitária, inclusive com experiências que enfocam a autodeterminação da população aborígine. Em El Salvador, o mais novo sistema de saúde de acesso universal, estruturado a partir de experiências exitosas de participação popular, por meio do Fórum de Saúde, também se revela essa nova experiência. Esses e outros relatos apresentados permitem questionar qual perspectiva de modelo de saúde se deve buscar e se os parâmetros de realização em torno dos ODS são os melhores para atingir saúde para todas as pessoas.

A outra questão em torno dos ODS concerne à própria estrutura de poder global, que tem como um de seus aspectos a governança em saúde, outro enfoque do Relatório. $\mathrm{Na}$ década de 70, a OMS passa, junto a diversas outras agências globais, pela pressão exercida por países do então chamado terceiro mundo, para que se aproximasse das suas demandas específicas. Esse movimento ficou conhecido como 'nova ordem econômica internacional' e teve como um de seus marcos, na área de saúde, a Conferência de AlmaAta e sua declaração homônima. Desde esse tempo, a despeito da sua aproximação com o sul global, a agência atravessa uma intensa transformação na sua estrutura de poder ${ }^{3}$. Enquanto em 1978, época de Alma-Ata, $80 \%$ dos recursos da agência eram oriundos dos recursos obrigatórios dos Estadosmembros, em 2011, o quadro já praticamente 
se invertia, com essa fonte respondendo por apenas $25 \%{ }^{4}$.

O setor da filantropia, conforme apontado no GHW5, tem crescido notavelmente nas últimas duas décadas, totalizando atualmente 200.000 fundações no total, 86.000 nos Estados Unidos, 10.000 no México, 2.000 na China e cerca de 1.000 no Brasil. Essas fundações gozam de representação em órgãos nacionais e internacionais inclusive na OMS, onde a Fundação Bill e Melinda Gates, por exemplo, ocupa espaço privilegiado de poder de decisão. O GHW5, crítico do papel de algumas dessas entidades, aponta que elas acabam por não fomentar a distribuição da sua riqueza, assim como 'marcam' as suas contribuições com intervenções específicas que lhes dizem interesse. Na área de saúde, especificamente, o Relatório aponta o viés imbuído no seu modo de funcionamento, que envolve aplicar um modelo de negócios à medição de resultados, apoiar-se em soluções tecnicistas que não levam em conta características locais, fomentar a participação privada em sistemas de saúde, além dos impactos para a governança global em saúde, especialmente em relação à transparência e aos mecanismos de responsabilização.

\section{Colaboradores}

Falcão M (0000-0002-2963-0159)*, Odeh M (0000-0003-4855-5761)*, Giugliani S (00000001-9947-2830)* contribuíram igualmente na elaboração do manuscrito.

\section{Referências}

1. Global Health Watch. Global Health Watch 5: An Alternative World Health Report. Londres: Zed Books; 2017.

2. Biehl J, Petryna A, editores. When people come first: critical studies in global health. Nova Jersey: Princeton University Press; 2013.

3. Ventura D, Aguilar Perez F. Crise e reforma da organização mundial da saúde. Lua Nova. 2014;

(92):45-77.

4. Legge D. Future of WHO hangs in the balance. Bmj. 2012; (345):e6877.

Recebido em 08/06/2019 Aprovado em 14/112019

Conflito de interesses: inexistente

Suporte financeiro: não houve 